Canadian Studies in Population, Vol. 30(1), 2003, pp. 35-50

\title{
Reflection on Population Forecasting: From Predictions to Prospective Analysis
}

\author{
Anatole Romaniuc \\ Adjunct Professor \\ Department of Sociology \\ University of Alberta \\ Edmonton, Alberta, Canada
}

In tribute to Anatole Romaniuc,

the Editor offers this reprint of his earlier published work

that appeared in Canadian Studies in Population, Vol. 10(2), 1994

\begin{abstract}
The notion of predictability, central to the conventional meaning given to projection, is de-emphasized, and that of analytical credibility stressed. The usefulness of a projection is to be judged by the extent to which it contributes to decisions shaping the future. The author explores the epistemological base for this reconceptualization of the projection as an instrument of "creating" rather than "discovering" the future. To this end, he turns to the contemporary developments in the philosophy of science.
\end{abstract}

Key Words: Population forecasting, predictability, analytical credibility 
Anatole Romaniuc

Résumé

La notion de prédictibilité, qui occupe une place centrale dans la théorie classique des perspectives du future, est substituée par celle de crédibilité analytique. L'utilité d'une perspective depend davantage de la mesure dans laquelle elle contribue à la prise des decisions susceptibles de modeler l'avenir. L'auteur explore la vase épistémologique de la redefinition de la perspective en tant qu'insturment de "creation" plutôt qu'instrument de"découverte", de l'avenir. La philosophie de science contemporaine lui sert de matière de réflexions.

Mots-Clés: Population forecasting, predictability, analytical credibility

\section{Introduction}

To begin my paper ${ }^{1}$, I chose a quote from the famous Italian writer, Umberto Eco (1989:199), who in turn borrowed it from Talmud:

"Whoever reflects on four things, it were better he had never been born: that which is above, that which is below, that which is before, and that which is after."

The last part of the quote is particularly pertinent to my theme. We will see that any attempt to foretell the future is a gamble. Yet, the future is as much an existential part of ourselves as are the present and the past. The question is rather how the future is to be perceived or construed.

Though inquiry about future evolution of population has a long history, forecasting as a utilitarian endeavour is of rather recent making. It is only in the past two or three decades that forecasting has evolved into a profession sui generis, and a business on a respectable scale.

Population forecasting is now part and parcel of public administration and private business. The advent of electronic technology in data manipulation and the blossoming of statistical modeling have no doubt been factors in its growth. But a more pervasive inducement to engage in forecasting has to do with present-day bureaucracy, to use Galbraith's term - committed to a management practice which relies heavily on planning and quantitative evaluation of the 
Reflection on Population Forecasting:

From Predictions to Prospective Analysis

anticipated impact of programmes and policies. This "anticipatory management" is very much part of the management culture of democratic society and of a free market economy.

There are three ways of looking at population forecasting or, to use a more neutral, less value loaded term, population projection, namely: fist as prediction, second as simulation, and third as prospective analysis. Let me review, one by one, each of these three types of population projection. Much of what I will b e arguing holds true for projections in many other social fields; it is not unique to demography.

\section{Projection as Prediction}

Let us remind ourselves first that the art of population conjecture grew out of a deliberate effort to predict the evolution of population. Indeed it was long believed that the evolution of human society was governed by laws similar to those found in the physical world and that it was incumbent upon scientists to discover them and put them to practical use, including prediction of the future. The following quotation from Marquis de Concorcet (1988:265), a major figure of the eighteenth-century French Enlightenment, captures the mood of the time:

"If man is able to predict, with almost complete assurance, those phenomena whose laws he understand, ... he can, using his experience of the past, predict the future with a high degree of probability; when then should it be thought fanciful to sketch with some degree of plausibility the destiny of the human race, based on its history?" (Translated from the 1988 French Edition)

From our present-day vantage point, Condorcet may sound overly optimistic, if not far-fetched. But the controversy between the proponents of social determinism and those of indeterminism is far from settled (Gurvitch, 1963). Some believe that social events are part of a kind of pre-ordained, "law-like" process and are, as such, predictable. Others believe in the historical uniqueness and, hence, the inherent unpredictability of social events.

For the rationalization of demographic projection as prediction, one could turn to three different theoretical frameworks. The first implies the existence of a general law of population, and the second that of statistical regularities; the third one involves a probabilistic or stochastic conceptualization of demographic events.

In the way of a broad theoretical framework for forecasting population, two well-known demographic theories come to mind: logistic growth and demographic transition. Logistic growth theory describes an itinerary whereby, 
after initial growth difficulties, the population sets out on a course of rapid expansion. As higher levels of density are reached and growth is increasingly frustrated in a finite space, population expansion tapers off to an eventual halt. A mix of the Malthusian vision of exponential population growth and of the law of diminishing returns, logistic growth theory is reflective of the relatively simple relationship between population and the environment under the conditions prevailing in pre-modern, agrarian societies. Its appealing sociobiological (or ecological rationalization (Quetelet, 1869) and elegant mathematical formulation (Verhulst, 1844) made it influential among social scientists of the second half of the nineteenth and first half of the twentieth centuries. It gave rise to many empirical statistical applications - curve fitting to observed trends in a variety of social fields, and forecasting.

Since the Second World War, however, logistic growth theory has been largely upstaged by the demographic transition theory, its younger cousin which is better tuned to the conditions of a modernizing society. It postulates three stages of evolution - from a high fertility/mortality equilibrium to a low fertility/mortality equilibrium, punctuated by a stage known as "demographic transition". The transitional period is characterized by rapid population growth, as declines in mortality, induced by economic and medical progress, outpace the declines in fertility that are slower to respond to such progress. Rather than "density", the theory stresses "growth", a more meaningful demographic variable in the context of a dynamic technology-driven economy. Furthermore, it focuses directly on mortality and fertility and their determinants, rather than on their end product - population size.

Yet, in spite of its greater theoretical depth and indisputable analytical superiority, the demographic transition is no better than the logistic growth theory for providing a reliable basis for forecasting. Each historical experience of demographic change is unique in more than one respect. To be sure, one may well expect, for example, fertility to decline in tropical Africa as that region undergoes modernization. But unless one can e more precise about the timing and speed of the decline, generalizations such as those offered by the demographic transition theory cannot serve as a modus operandi for making population forecasts. Or who can guess the future course of mortality now that AIDS has reached epidemic proportions in some regions of Africa? All too frequently, such unexpected events play havoc with what otherwise appear to be predictable, long-term demographic trends.

Having failed in their bid to uncover a general law of demographic growth as a basis for prediction, forecasters have turned for assistance to observed statistical regularities of a mere limited scope. Some denote simple associative relationships; others imply cause/effect relationships; still others typify structural stability, developmental inertia or a sequentiality of events. For example, fertility declines with an increase in female job opportunities and 
Reflection on Population Forecasting:

From Predictions to Prospective Analysis

earnings outside the home. Economic development brings higher literacy, lower mortality and, ultimately, lower fertility.

Keyfitz (1982:747), a well known demographer, took a critical look at the theories and statistical models embodying such relationships, with the aim of discovering their utility to forecasters. He concluded that though they may be useful in explaining the past and, in some cases, formulating policies, they are not very useful for forecasting.

"We have found few instances in which understanding of the past and the conditional relation can be brought to bear on forecasting."

Observed relationships held constant or constrained to vary in certain fashion may well be helpful in making "conditional projections". But what users are after, Keyfitz points out, is dynamic, unconditional and not ceteris paribus types of projections. Conditional projections evade their real query of what actually or probably will happen. Yet it is doubtful that the past can provide any guidance for the future. There is no symmetry between explanation of the past and prediction of the future, between retrodiction and prediction.

A renewed effort has been made in recent years to rekindle the predictability concept through a probabilistic approach to projections. One can cite as an example Stoto's (1983) attempt to construct confidence limits for future projections from errors (differences between projected and actual population parameters) in past projections.

"The discovery of stable error distributions allow us to transform the results of the historical analysis into confidence intervals for future populations. These confidence intervals reflect the best efforts of competent demographers in the past, and should be a reliable guide to the present generation's ability to predict the future."

The theoretical foundation of a probabilistic approach to projections is not clear, though one could think of two possible interpretations. The first is to think of a collection of projections analyzed for errors, as if it were a random sample drawn from a much larger universe of projections. An attempt such as Stoto's may be seen as being, in theory, of this kind. In practice, however, it is more like an extrapolation of past projection error - with all the pitfalls inherent in any method which extrapolates past trends.

Another interpretation one could offer is that of predictions based on a presumably valid population law (or statistical regularity) - subject, however, to random errors and departures from the trend, to accidents or to deliberate human interference. For a remote analogy, one may look to the application of statistical probabilities to certain laws in physics. A case in point is Heisenberg's principle 
Anatole Romaniuc

of uncertainty, wherein an electron's position and velocity at any instant can be determined only with a certain probability.

With all the accumulation of knowledge on how demographic processes work (or more precisely, have worked in the past) and with all the sophistication of forecasting methods, we must concede to being no closer to getting a glimpse of the future than we were before. The future remains as opaque and elusive to the forecaster's eye as ever. Unlike some natural processes, social processes are evolutionary, non-repetitive, irreversible, and hence, unpredictable. Nowhere does Heraclitus's aphorism - "you can't step twice into the same river" - apply better than to the ever-changing process of social life. Moreover, in the modern world, changes occur at ever greater speed, and they are increasingly triggered by man's deliberate intervention. But while the social process is not preordained or law-like, neither is it chaotic and mindless. It does not lack coherence and order, and it is teleological in the sense of goal-triggered human action.

Practitioners in the art of conjecture about the demographic future must lower their sights. Probability, let alone certainty, is out of their reach; plausibility is the best that can be hoped for. In most cases, however, projection is little more than an exercise in future-oriented simulation. It is to this subject that we now turn.

\section{Projection as Simulation}

From their initial, narrowly focused heuristic uses - mainly teaching - forwarddirected demographic simulations have increasingly broadened their scope to include policy applications. They are now being used as analytical tools in governmental decision-making and in the evaluation of population-related policies.

I should not dwell much on this type of projection because it does not raise epistemological issues of the complexity that we encountered in discussing projection as prediction. Simulations are prediction-neutral. No attempt whatsoever is made to predict the future. They are, by definition , "conditional" projections, and tautological in the sense of one set of parameters (input) being transformed into another set of parameters (output) that are relevant to the problem at hand. Demographic simulations present a large bag from which to choose. They vary widely with regard to their purpose and technical complexity.

A distinctions could be made between "process-oriented" simulations and "goal-oriented" simulations. In the first case, simulations are designed to generate outcome in terms of, say, the population size and age structure implied in an observed or assumed demographic process of fertility, mortality and 
Reflection on Population Forecasting:

From Predictions to Prospective Analysis

migration. They can be used to assess the implications of specific population policies, such as Canada's immigration policy on population size an age structure or the implications of China's one-child policy on population growth and family structure.

In the second case, that of the goal-oriented simulations, a demographic "goal" is set up on some grounds; then a simulation is performed to determine the optimum combination of factors or paths leading to that goal.

Another distinction can be made between "single-purpose" and "multi-purpose" simulation models. Confined to a few demographic variables, single-purpose models are relatively simple in their premises, as are the questions they address. Their underlying hypotheses may be simpler, and validation easier. Such models are tailored to specific tasks and can be very useful as heuristic tools for planners and researchers trying to elucidate specific population policy issues.

Multi-purpose models are another matter. Large-scale and multidimensional constructs, they invariably involve highly complex computer operations and call for the input of many socio-economic and demographic factors. They are often designed to reveal the long-term implications of the interaction of these factors. The case in point is the model built by Meadows (1974) and his associates at the Massachusetts Institute of Technology that simulates the future global development of human society.

Some people expressed reservations as to how useful these complex multipurpose simulations can e as planning and policy instruments. To quote Arthur and McNicoll (1975:151), "If there is one underlying source of weakness in these models, it is their aspiring to be multi-purpose. It is this that makes them large, structurally inflexible, overdressed in side issues, and beyond proper validation."

\section{Projection as Prospective Analysis}

Prospective analysis is conceptually a more complex entity - neither prediction nor simulation, within the meaning assigned to these terms above. It embodies some of the elements of the two, and certain other features. If one pictures the transition from simulation to prediction on a continuum, with predictability ideally increasing in degrees along that continuum, then prospective analysis would be found somewhere midway along the axis. The hallmarks of this type of projection are "potentially" rather than "inevitability", and "plausibility" rather than "certainty" or "probability".

There are a certain number of requisites that a sound prospective analysis must meet. Let me go over them one by one. 
Anatole Romaniuc

\section{Analytical Credibility}

The notion of analytical credibility is at the very heart of this conceptualization of projections. The argument underlying the projection assumptions must be persuasive both to the developer's professional peers and to users. This calls fro an analytical paradigm, designed in such a way as to assist in formulating "credible" assumptions about the behaviour of the parameters to be entered into the projection algorithm.

The particular configuration of the paradigm will depend on the state of the art of demographic analysis in general and on the nature of the particular parameter to be projected. Some of its desirable common features can, however, be singled out. While flexible enough to accommodate new data and methodological advances, it must be capable of reapplication without major alteration. Reinventing the wheel for each new round of projections is wasteful of time and resources. Particular attention should be paid to the time series of "leading" indicators in order to get some reading of the direction of the trends and to detect any signals of possible reversals in the near future. But not only should the analysis rely heavily on those time series that may be regarded as harbingers of tomorrow, it should, furthermore, bring into its purview relevant policies and anticipated events deemed to influence demographic trends in the years to come. But, while doing all this, one should be conscious of cost and timeliness requirements. In other words, a projection model should possess analytical capabilities and yet be cost-effective. And this leads to the second requisite of prospective analysis.

\section{Minimizing the Input and Maximizing the Output}

Indeed, while advocating the need to base projection assumptions on a sound analysis, one should not lose sight of the fact that projection is not an academic exercise but is, for all practical purposes, a business; costs and benefits matter. The projection-maker must be cognizant of the up-front price tag accompanying the analytical input to projections. One must balance parsimony with efficiency, quality with timeliness. On the one hand, the number of parameters to be analyzed and manipulated (even in this age of powerful computers) must be minimized so as to reduce the cost of the operation. On the other hand, one must select parameters that have analytical potential. "Number crunching" does not in itself guarantee sound analysis. Hajnal's (1955) advice, "less computation and more cogitation", should be a constant reminder to those involved in making projections. Parameters with intuitive value are preferable to purely abstract mathematical parameters. Not only do the former assist in the understanding of the processes being analyzed but they also facilitate communication between producers and consumers of projections. 
Reflection on Population Forecasting:

From Predictions to Prospective Analysis

\section{The Frequency of Projections ${ }^{1}$}

While respecting certain periodicity, as a matter of policy, the revision of the existing projections or development of new ones should be based on analytical considerations, when, for example, the demographic situation has changed to justify a new round of projections.

\section{Single Versus Multiple Projections}

Current practice, generally speaking, makes allowance for a range of projections, based on alternative assumptions about future fertility, mortality, and migration. This in itself is reflective of intellectual reorientation away from belief in a population law and acceptance of a more pragmatic intellectual posture.

\section{Time Horizon ${ }^{2}$}

Demographic changes do not occur overnight. There is a certain inertia inherent to demographic tendencies. Projections over a period of 10 to 25 years is not an unreasonable venture. Anything beyond should be regarded as an exercise in simulation.

\section{The Usefulness of Projections}

If we accept the fact that population cannot be predicted, then why make projections? What purpose does it serve? The answer is that plausible assumptions can be made about demographic tendencies, and those assumptions may play a useful role in decision-making. Plausible assumptions are all that can be hoped for as a basis for "rational" decisions under conditions of uncertainty. This is not very different from what can be said about plans, projections or expectations in making decisions. More often than not, in real life, these various anticipations exceed or fall short of the actual attainments and have to be readjusted, in the course of time, to emerging conditions. Yet they have triggered new initiatives and actions. They are indispensable aids in managing the future.

In talking about the usefulness of projections, two points need to be emphasized. One refers to the notion of "understanding" and its bearing on decision making. "Understanding" the processes that lead into the future is important in preparing for it; "understanding is the only appropriate method of dealing with the uncertainty of the future conditions", wrote Ludwig von Mises (1963). 
Anatole Romaniuc

Therefore, throughout this paper, so much value is placed on the analytical credibility of projections.

The other point refers to the way the future is conceived as being either something that is to be discovered or something that is to be created. This distinction should be borne in mind when assessing the usefulness of projections. If gauged by the degree to which they predict population, the results may indeed by deceptive. But if the question is switched around by asking to what extent they have been instrumental (irrespective of whether they turn out to be right or wrong) in "creating" the future, judgment about their usefulness may become much more positive. A survey carried out among users of projections may indeed reveal some startling figures about the amount of money invested or traded, or about new schools and hospitals to be built as a result of population projections. Eventually, a welfare function may be discerned - namely, that we are better off with projections. Consequently, looking at projections from the perspective of "creating" the future casts a different light on their usefulness. It gives them a different twist from the conventional one emphasizing their predictive value. With Peter Drucker (1964), we shall ask "not what will tomorrow look like", but instead "what we have to tackle today to make tomorrow".

\section{The New Look at Forecasting: Its Epistemological Foundation}

Throughout this paper we have tried to clarify the meaning of projection in terms of prediction, simulation and prospective analysis. In doing this, I signaled some significant departures both in substance and in accent from the customary way of viewing the forecasting in the field of population, and by extension more generally in social future studies. Two distinctive features of the reconceptualization of the population forecasting proposed here afford restatement.

First and foremost, the notion of predictability, so central to the conventional meaning of the forecasting or projection, is de-emphasized. Instead, emphasis is placed on the analytical credibility of the projection work. This means turning away from the far too elusive goal implied in the former, to one implying improvability, and acceptability by the developers' professional peers and by the users of projections. In practical terms, this means making use of all professional skills available, within the confines of cost-effectiveness, to come up with analytically credible assumptions about the key parameters of the projection. What is being implied in this epistemological approach to projection is that we rid ourselves of the "oracle complex" and take a down-to-earth view of what in real life is the kind of projections government and private agencies engage in. Their practical and applied nature needs to be stressed. It is not a vague speculative vision of the more or less remote future that we have in mind when we sit down to develop projections but a set of numerical, time-bounded 
estimates of the demographic parameters designed to be used by government and private business in the decision making concerning the future, i.e., planning, programme and policy elaboration.

The other significant innovation in the manner in which projections are perceived, resides in the validation of their usefulness. What counts in not so much whether they turn out to be right or wrong, the extend to which they depart from the actual population, something that can be verified only post facto. What is far more important is whether and how they are used in the decisions that affect our future as individuals and as a collectivity. Clearly, the acceptance of a projection and the likelihood of its utilization depends a great deal on the quality of the work and the professional credibility its makers enjoy among peers and the users. Projections thus acquire features of a working tool and take a proactive stance rather than that of a passive contemplation of the future. They are turned into an instrument for creating rather than discovering the future.

This redefinition of the nature and the purpose of forecasting was partly prompted upon us simply by the lessons we learned from experience. We grew more mature and wiser. The repeated failure to "predict" the future population led us to take a more pragmatic and sober stance in the matter of future studies. $\mathrm{B}$ ut there are more profound reasons for this change in forecasters' moods. They have to be looked for in an intellectual frame of mind, in Weltanschauung fostered by the contemporary developments in science and philosophy of science (see in particular Prigogine and Stengers, 1984). The offshoot of these developments is a frame of mind that pays due attention not only to necessity (determinism), as the classical science did, but also to the chance and free will in order to understand more adequately the complexity of natural and social processes.

The classical, mechanical interpretation of the world, the cosmological world of Newton with its timeless reversible laws, has seen its sphere of action, the scope of its universality, significantly curtailed. Modern advances in physical science have given rise to a probabilistic, statistical description of physical world at its micro, most elementary particles, and at macro-levels of natural laws, more notably in chemistry and biology, that are irreversible.

The Plank's quantum mechanics, the Heiseberg principle of indeterminacy, the Second Law of thermodynamics, and entropy have revolutionized the interpretation of the world and more clearly revealed the extent of its complexity and diversity. To quote Prigogine and Stengers (1984:8): "We find ourselves in a world in which reversibility and determinism apply only on limiting simple cases, while irreversibility and random are the rules." Some processes are deterministic and reversible, and repetitive; others are probabilistic and irreversible, i.e., non-repetitive. 
But there is more than recasting the fundamental laws into a probabilistic, statistical mode in natural sciences, and substituting the notion of order and coherence for the earlier belief in immutable laws, in social sciences. Chance has made its entrée in the description of physical, biological, and social world. Instability, accidents, disequilibrium, and chaos are very much part of today's scientific vocabulary. Random and fortuitous events enter the descriptive schema of the world as entities which have their own existence, and not just a misnomer for our ignorance or, to paraphrase Poincaré (1947:65), those occurrences whose laws we ignore. After all, inverting Einstein's well known aphorism, God may play dices, and occasionally violate deliberately or inadvertently His own rules.

In the field of population, the forecaster is often faced with the anticipation of the reversals and turning points in what appears to be established trends. Take for example, the two probably most significant events on the landscape of the contemporary demographic developments in the Western world - the Babyboom, and the Baby-bust. The Baby-boom, in particular, appears to be completely at odds with the trends set up by the secular decline in fertility, even though we may well be tempted to explain it retrospectively, as an outcome of a unique historical setting of events - the Great Depression, World War II, and postwar economic prosperity (Romaniuc, 1991). As to the subsequent Babybust, though from an evolutionary perspective its advent is explainable rather nicely, it remains that it came as a total surprise to demographers. Even more puzzling is the out-break in recent years of AIDS as a significant factor in mortality. Not unlike biology, demography may well experience its own "random drifts". What in actual experience we have to contend with are derailments some of which may be "caused" by external events, and others by internal, sometimes very small imperceptible maladjustments, which however may have large scale effects. Whatever the source of these derailments may be, their nature and mechanisms escape out intelligence so utterly that we have no choice but to treat them for all intent and purpose as accidents.

The third and last element of our explanatory triad - the volition, the human will. The controversy between determinism and free will is as old as philosophical thought, and its resolution is probably beyond the pale of science's reach. As a basically metaphysical question, it may be ignored without serious penalty for the discussion of the issue at hand. It suffices to recognize here the role humankind, individually and collectively, is playing or can play in shaping its destiny. This is done in a number of ways. First through the discovery of scientific laws, whether deterministically or statistically defined, and their technological applications. In this respect, humankind went as far as altering nature itself and even its own making (the case in point being genetic engineering). Secondly, humans have demonstrated in the course of time their capacity for social engineering. And, if in some areas society was reluctant to bring to bear this power, it was because of the actual or perceived high cost (economic or social) or lack of political will. 
Recognition of humankind's ability on its own volition to affect social developments has implications for forecasting. It is often argued that projections can be "self-fulfilling" or "self-defeating" prophecies, depending on whether or not the anticipated outcome is viewed by the public, i.e., its political leadership, as desirable. To put it more generally, our actions may be prompted by both past events and "knowledge" of the future, i.e., by present antecedents and consequents. By mere action of forecasting the future, we may actually contribute to its creation.

The broader question, often raised, is whether statistical information, including that contained in projections, can contribute in any discernable, meaningful way to the resolution of public problems. The answers to this question are often tainted by the sense of helplessness in the face of bureaucratic inertia, government's shortsightedness and hard-pressed search for short-term solutions. My own feeling is that statistical information has a role, sometimes directly, but probably more often incrementally over time to the extent it contributes to educating the public and decision makers about issues. The policy effectiveness of information, be it statistical or scientific, can be enhanced by closer cooperation of various disciplines toward the resolution of problems of public interest. As Keyfitz (1993) so pointedly argued in a recent paper, the very least the experts working on a problem from their respective disciplines could do, is to make the arguments underlying their assumptions transparent and thus avoid sending contradictory messages to the public and to policy makers. Democracy is at its best when it deals with issues on which there is a high degree of public consensus.

What is taking place in modern thought is the emergence of an intellectual framework whereby the earlier antinomies between necessity, chance and will are reduced, while at the same time they are recognized as factors in natural and social processes. Lesourne (1985:559) puts it succinctly:

"Chance, necessity, will: these are three elements of creation and destruction, of permanence and change, of adaptation and ossification. Chance produces a random sequel to the situation of a given moment; necessity involves one variable determining another on the macro and micro level; will substitutes, for passive elements, actors capable of formulating and pursuing strategies." (Translation from French)

In other words, social process is neither deterministic nor is it the outcome of free will or sheer chance. Rather, it is a combination of all of these. The modern thought brings the sciences and the humanities closer; it clearly recognizes the importance of the "interaction of man and nature as well as of man with man." (Prigogine and Stengers, 1984:7) 
This frame of mind has implications for the projection's perception and design. Were demography to obey only laws, what ever they may be, the scope of projection's maker would be primarily limited to developing and improving mathematical functions of curve fitting and extrapolation into the future. The deliberate or spontaneous human intervention to modify the course of events adds to the complexity, and the excitement, of the task. It makes forecasters broaden the scope of their analysis by including human volition. Then, there are accidents and chance. Rather than disposing of them in the way of a cautionary statement, "barring extraordinary events", that often preface the presentation of projections, they are recognized as inherent to processes of life, and force us into the acceptance of uncertainty as a fundamental feature of the future. Uncertainty about the future, as we explore its limits and potentials, can prompt us into action and creativity. With Erich Fromm (1947), we may say: "Uncertainty is the very condition to impel man to unfold his powers."

\section{Acnowledgements:}

Reprinted with permission of the editor of Canadian Studies in Population. This article appeared in Canadian Studies in Population, Volume 10, Number 2 (1994).

\section{Endnotes:}

1. Delivered at the Department of Sociology, University of Alberta, on November 25, 1993, in memory of Enid Charles. For a portrait of the personality and intellectual legacy of this distinguished pioneer of Canadian demography, see Sylvia Wargon (1992). This paper is a shorter version of an earlier work, Projection as Prediction, Simulation and Prospective Analysis, published in Population Bulletin of the United Nations, No. 29, 1990. It contains, however, a section not published hitherto, in which the epistemological base of forecasting is discussed.

2. For a full exposition of the argument regarding this requisite and the next two, refer to my article under Endnote 1.

\section{References:}

Arthur, W. B. and G. McNicoll. 1975. "Large-scale simulation models in population and development. What use to planners?" Population and Development Review. 1(2): 251-265.

Condorcet, Marquis de. 1988. Esquisse d'un tableau historique des progress de l'esprit humain. Paris, France: Flammarion. 
Drucker, P. F. 1964. Managing for Results. New York, N. Y.: Harper \& Row. Eco, U. 1989. Folucault's Pendulium. New York, N. Y.: Ballantine Books.

Fromm, E. 1947. Man for Himself: An Inquiry into the Psychology of Ethnics. New York, N. Y.: Holt, Rinehart and Winston.

Gurvitch, G. 1963. Déterminismes sociaux et liberté humaine. Paris, France: Presses Universitaires de France.

Hajanal, J. 1955. "The prospects for population forecasts," Journal of the American Statistical Associatiion. 50(270): 309-322.

Keyfitz, N. 1993. Resolution of inter-disciplinary contradictions and the use of science in policy. PDOD Paper No. 24. Laxenburg, Austria: International Institute for Applied Systems Analysis, IIASA.

Keyfitz, N. 1982. "Can knowledge improve forecasts?" Population and Development Review. *(4): 729-751.

Lesourne, J. 1985. Introduction à la recherché d'une théorie de l'autoorganisation. Economic appliquée (Paris). XXXVII (3-4): 259-567.

Meadows, D. I., Et al. 1974. Dynamics of Growth in a Finite World. Cambridge, MA.: Wright-Allen Press.

Mises, L. von. 1963. Human Action: A Treatise on Economics. $3^{\text {rd }}$ Edition. Chicago: Contemporary Books.

Poincaré, H. 1947. Science et méthode. Paris, France: Flammarion.

Prigogine, I. And Stengers, I. 1984. Order Out of Chaos. New York, N. Y.: Bantam Books.

Quetelet, A. 1869. Physique sociale ou essai sur le développement des facultés de l'homme. Bruxelles, Belgium.

Romaniuc, A. 1991. "Fertility in Canada: Retrospective and prospective," Canadian Studies in Population. Vol. 18(2): 56-77.

Romaniuc, a. 1990. "Population projection as prediction, simulation and prospective analysis," Population Bulletin of the United Nations. Vol. 29: 1631.

Stoto, M. 1983. "The accuracy of population projections," Journal of the American Statistical Association. Vol. 78(381): 13-20. 
Anatole Romaniuc

Verhulst, P. F. 1884. Recherches mathématiques sur la loi d'accroissement de la population. Mémoires de L'Académie royale de Belgizue, Tome XVIII.

Bruxelles, Belgium.

Wargon, S. T. 1992. "Women in demography in Canada," Canadian Studies in Population. Vol. 19(2): 181-215. 
Reflection on Population Forecasting: From Predictions to Prospective Analysis 